Rev. Bras. Saúde Prod. Anim., Salvador, v.14, n.1, p.132-141 jan./mar., 2013 http://www.rbspa.ufba.br ISSN 15199940

\title{
Variabilidade espacial das características ambientais e peso de frangos de corte em galpão de ventilação negativa
}

\author{
Spatial variability of the environmental characteristics and weight of broilers in shed \\ negative ventilation
}

\author{
SILVA, Elisson Gomes da ${ }^{1^{*}}$; SANTOS, Antônio Clementino dos ${ }^{2}$; FERREIRA, Caio \\ Leonardo Silva ${ }^{1}$; SOUSA, Joana Patrícia Lira de; ROCHA, José Mário Lopes da ${ }^{1}$; \\ SILVEIRA JÚNIOR,Otacílio ${ }^{1}$
}

\begin{abstract}
${ }^{1}$ Universidade Federal do Tocantins, Escola de Medicina Veterinária e Zootecnia, Programa de PósGraduação em Ciência Animal Tropical, Araguaína, Tocantins, Brasil.

*Endereço para correspondência: elisson.gomes@uol.com.br
\end{abstract}

\section{RESUMO}

Objetivou-se estudar a variabilidade espacial das características ambientais e do peso de frangos de corte criados em galpão com ventilação negativa. $\mathrm{O}$ trabalho foi realizado em galpão industrial no município de Aguiarnópolis (TO), com lote misto de 30.000 frangos de corte da linhagem Coob, com 42 dias de idade, nos horários críticos de alta temperatura ( $12 \mathrm{~h}$ às $15 \mathrm{~h})$, composto por sistema de ventilação negativa e sistema de nebulização. As coletas das variáveis analisadas foram realizadas em 1 dia em malha regular totalizando 124 pontos, distribuídos uniformemente ao longo do galpão, com espaçamento de $4 \mathrm{~m}$ entre cada ponto em 31 linhas dispostas. As variáveis ambientais coletadas foram: temperatura do ar, umidade relativa do ar, velocidade do vento além da temperatura da cama. Para a verificação da variabilidade do peso das aves foram capturadas aleatoriamente, a cada ponto de coleta, uma ave macho seguida da captura de fềmea. As variáveis estudadas apresentaram de moderada a forte dependência espacial. Através dos mapas de variabilidades espaciais pode-se observar que a desuniformidade das características ambientais provocam igual efeito no peso vivo dos animais, definindo, assim, áreas específicas que comprometem o desempenho dos frangos de corte, onde as variáveis: umidade relativa do ar, temperatura ambiente, temperatura de cama, velocidade do vento e umidade estão acima do recomendado para o conforto térmico animal. As variáveis ambientais temperatura do ambiente, umidade relativa do ar, velocidade do vento além da temperatura de cama influenciaram diretamente na variabilidade do peso dos animais.

Palavras-chave: dependência espacial, geoestatística, krigagem.

\section{SUMMARY}

The objective was to study the spatial variability of environmental characteristics and weight of broilers reared in shed negative ventilation. The work was conducted in municipality of industrial shed Aguiarnópolis, Tocantins state, with mixed batch of 30,000 broiler strain Coob with 42 days in critical hours of high temperature (12h to $15 \mathrm{~h}$ ), composed of negative and misting ventilation system. The gathering of the variables analyzed were performed on 1 day at regular grid totaling 124 points, evenly distributed throughout the house, with $4 \mathrm{~m}$ spacing between each point on 31 lines arranged. The environmental variables were collected: air temperature, relative humidity, wind speed besides the temperature of bed. For the verification of weight variability of birds, animals were captured randomly at each collection point, a male bird first, then a female. The variables studied showed moderate to strong spatial dependence. Through the maps of spatial variability can be observed that the imbalance of environmental characteristics cause equal effect on body weight of animals, thereby defining specific areas that affect the performance of broiler chickens, where the variables: relative humidity, temperature environment, bed temperature, wind speed and humidity are above recommended for thermal comfort. Environmental variables like ambient temperature, bed temperature, relative humidity and wind speed directly influence the variability of animal weight.

Keywords: geostatistics, kriging, spatial dependence. 


\section{INTRODUÇÃO}

$\mathrm{O}$ aumento da produtividade na avicultura industrial é consequência do sinergismo entre alguns fatores, dos quais se destacam: genética de alta qualidade e as tecnologias relacionadas ao conforto térmico dos animais que possuem metabolismo elevado com alta produção de carne em curtos espaços de tempo, existindo preocupação constante com faixa ótima de conforto térmico, que se adapte às características biológicas, para manter os índices de produção (SILVA et al., 2007).

Fator importante para o sucesso da produção avícola é o monitoramento e controle eficiente do ambiente de criação. De acordo com Pereira et al. (2011) este ambiente pode ser classificado em térmico, aéreo, físico, biológico, acústico e social. Todos esses ambientes estão interrelacionados e os seus efeitos são difíceis de serem mensurados com precisão.

$\mathrm{Na}$ região Norte do Brasil o clima predominante é o tropical, com temperaturas médias elevadas durante todo o ano. Sendo assim, tornam-se necessárias, o uso de modificações ambientais, primárias ou secundárias para o combate do estresse térmico dos animais, permitindo que eles possam produzir e reproduzir com eficiência (BORGES et al., 2003; NAZARENO et al., 2009).

A utilização de galpão de ventilação negativa vem sendo, uma das estratégias mais utilizadas pelos avicultores para a promoção do ambiente mais próximo do exigido pelo animal em busca da máxima expressão de seu potencial genético, pois tem como princípio a possibilidade de controle total das características ambientais.

De acordo com Jones et al. (2005), os momentos finais, mais pronunciadamente as últimas semanas de criação dos frangos industriais, assumem significativa importância no que diz respeito ao conforto térmico. É nesta fase onde ocorre as maiores produções de calor por parte dos animais, e este incremento pode afetar de forma negativa o desempenho das aves (BORGES et al., 2003).

A variabilidade espacial das características ambientais, dos galpões de frangos de corte é fator preponderante na tomada de decisões quanto ao manejo a ser utilizado. $\mathrm{O}$ conhecimento da variabilidade espacial e a construção de mapas de isolinhas, através do método de krigagem (MATHERON, 1963), podem servir como ferramentas de significativo valor quando aplicados no manejo correto de animais confinados, instalações e equipamentos.

Objetivou-se estudar a variabilidade espacial das características ambientais e do peso de frangos de corte criados em galpão de ventilação negativa aos 42 dias de idade.

\section{MATERIAL E MÉTODOS}

O trabalho foi desenvolvido em galpão industrial na região do Bico do Papagaio (Norte do Tocantins), localizado no município de Aguiarnópolis (TO), com latitude de $6^{\circ} 34^{\prime} 20,27^{\prime \prime} \mathrm{S}$ e longitude de $47^{\circ} 29^{\prime} 1,80^{\prime \prime} \mathrm{O}$.

O clima da região é do tipo tropical úmido, mantendo-se quente durante todo o ano, com temperatura média máxima de $32^{\circ} \mathrm{C}$ e mínima de $20^{\circ} \mathrm{C}$. Estação definida de chuvas entre os meses de novembro a maio, e uma estação seca entre os meses de junho a outubro, com precipitação anual acima de 1.700 milímetros.

O galpão avaliado possuía dimensões de $150 \mathrm{~m}$ de comprimento por $14 \mathrm{~m}$ de largura e estava com lote misto de 30.000 frangos de corte da linhagem Coob com 42 dias de idade, composto por sistema de ventilação negativa equipado com onze exaustores dispostos na extremidade oeste do aviário, além de abertura para entrada de ar na 
extremidade oposta, com capacidade de movimentação e renovação do ar de 2,0 a $2,5 \mathrm{~m} / \mathrm{s}$ possuía, também, sistema de aquecimento por forno a lenha, fixo, localizado no centro do galpão, a $75 \mathrm{~m}$ de comprimento e $7 \mathrm{~m}$ de largura, utilizado para aquecimento do lote na fase inicial criação. $\mathrm{O}$ sistema de nebulização instalado em todo o galpão estava distribuído em linhas transversais, com 140 bicos, tendo seu funcionamento controlado por termostato e cronômetro, e acionado quando a temperatura ambiente ultrapassava $24^{\circ} \mathrm{C}$, desligados quando a temperatura retornava a esse nível.

Todas as variáveis analisadas foram coletadas em um único dia, com as aves com 42 dias de idade, entre os horários críticos de alta temperatura (12h às $15 \mathrm{~h}$ ), em 124 pontos obedecendo malha regular uniformemente distribuídos ao longo do galpão, com espaçamento de $4 \mathrm{~m}$ entre cada ponto em 31 linhas dispostas.

Para medição das características ambientais, os aparelhos foram mantidos a uma mesma altura $(0,5 \mathrm{~m}$ do piso). As variáveis ambientais: temperatura do ar, umidade relativa do ar e velocidade do vento foram coletadas com o equipamento Termo-Higro-Anemômetro Luxímetro Digital da marca Instrutherm, Modelo THAL - 300. Esse equipamento permite a medição da temperatura entre $-100^{\circ} \mathrm{C}$ e $1.300^{\circ} \mathrm{C}$, umidade relativa do ar entre $10 \%$ e $95 \%$ e velocidade do vento de 0,4 a $30,0 \mathrm{~m} / \mathrm{s}$. Para temperatura da cama em graus centígrados $\left({ }^{\circ} \mathrm{C}\right)$ foi utilizado termômetro infravermelho, modelo 300T2.

Para a verificação da variabilidade do peso dos frangos de corte, foram capturadas aleatoriamente uma ave macho seguida da captura de uma fêmea, obedecendo ao mesmo esquema de coletas em malha regular utilizado para as variáveis ambientais totalizando, assim, 124 pesos de aves macho e 124 pesos de aves fêmeas.
As medidas descritivas avaliadas foram: média, mediana, coeficiente de variação (CV), coeficiente de assimetria e curtose com o auxilio do software Assistat versão 7.5 beta (SILVA, 2008). Utilizou-se o teste de Kolmogorov-Smirnov (KS) a 5\% de probabilidade para testar a hipótese de normalidade. De acordo com os valores de $\mathrm{CV}$, a variabilidade dessas variáveis foram classificadas, segundo Warrick \& Nielsen (1980) em baixa $(\mathrm{CV}<12 \%)$, média $(12 \%<\mathrm{CV}<62 \%)$ e alta $(\mathrm{CV}>62 \%)$.

As variabilidades espaciais foram determinadas por meio de exames de semivariogramas obtidos, ajustados a modelos teóricos para obtenção de seus parâmetros (pepita, patamar e alcance). Para verificar a presença de anisotropia, foram calculados semivariogramas para quatro direções, com intervalos de $45^{\circ}(0$; $45 ; 90$ e $135^{\circ}$ ). Em nenhum dos casos foi verificada evidente anisotropia no conjunto dos dados. Portanto, foram assumidos semivariogramas de $90^{\circ}$.

Após o ajuste dos semivariogramas os dados foram aplicados diretamente na interpolação por krigagem para a geração dos mapas das variáveis: temperatura do ambiente $\left(\mathrm{C}^{\circ}\right)$, temperatura de cama $\left(\mathrm{C}^{\circ}\right)$, umidade relativa do ar (\%), velocidade do vento $(\mathrm{m} / \mathrm{s})$, peso do macho $(\mathrm{kg})$ e peso da fêmea $(\mathrm{kg})$.

$y(h)=\frac{1}{2 N(h)} \sum_{i=l}^{N(h)}[Z(x i)-Z(x i+h)]^{2}$

Sendo $\mathbf{N}(\mathbf{h})$ o número de pares de valores experimentais medidos em $\left[\mathrm{Z}\left(\mathrm{x}_{\mathrm{i}}\right), \mathrm{Z}\left(\mathrm{x}_{\mathrm{i}}+\right.\right.$ $h)$, separados pelo vetor $h$. No presente estudo, os valores de $\mathbf{Z}$ foram os atributos químicos avaliados, enquanto os valores de $\mathbf{x}_{\mathbf{i}}$ e $\mathbf{x}_{\mathbf{i}}+\mathbf{h}$ foram definidos de acordo com a localização geográfica das amostras realizadas no campo. $\mathrm{O}$ ajuste dos semivariogramas possibilitou definir os valores do efeito pepita $\left(\mathrm{C}_{0}\right)$, do alcance (A) e do patamar $\left(C+C_{0}\right)$. A seleção do 
modelo teórico foi realizada, observandose a soma do quadrado dos resíduos (SQR), coeficiente de determinação $\left(\mathrm{R}^{2}\right)$, maior grau de dependência espacial (GDE).

Para análise do grau de dependência espacial (GDE) das variáveis foi utilizada a relação $\mathrm{C} /\left(\mathrm{C}+\mathrm{C}_{0}\right)$, classificada segundo Robertson (1998) como forte (GDE $\geq$ $0,75)$, moderada $(0,25 \leq \mathrm{GDE}<0,75)$ e baixa dependência (GDE $<0,25)$.

Os modelos de semivariogramas considerados foram o linear, o esférico, o exponencial e o gaussiano, sendo ajustados por meio do programa $\mathrm{GS}+{ }^{\circledR}$ (ROBERTSON, 1998). Os mapas de isolinhas que representam a distribuição espacial das variáveis foram obtidos através do programa Surfer ${ }^{\circledR}$.

\section{RESULTADOS E DISCUSSÃO}

Não houve simetria nas variáveis estudadas. Os dados mostram que a temperatura ambiente, temperatura de cama, umidade relativa do ar e peso de fêmeas possuem assimetria positiva, enquanto velocidade de vento e peso de machos possuem assimetria negativa (Tabela 1). Os valores da média e mediana de todas as variáveis estudadas foram próximos, significando que os dados possuem ou se aproximam da distribuição normal (LITTLE \& HILLS, 1978).

Coeficientes de variação (CV) com valores elevados podem ser considerados como os primeiros indicadores da existência de heterogeneidade nos dados (Tabela 1). Segundo Warrick \& Nielsen (1980) os valores de CV são classificados em baixo $(\mathrm{CV}<12 \%)$, médio $(12 \%<\mathrm{CV}<62 \%)$ e alto $(\mathrm{CV}>62 \%)$. A temperatura ambiente, temperatura de cama, umidade relativa do ar e pesos apresentaram baixa variabilidade no ambiente estudado, somente a velocidade do vento apresentou coeficiente de variação médio. De acordo com Faria et al. (2008) a alta variabilidade encontrada no parâmetro velocidade do vento, pode ser explicada pelo fato dessa característica mudar sua magnitude e direção constantemente com variações altas em curtos intervalos de tempo.

Tabela 1. Estatística descritiva para as variáveis ambientais temperatura ambiente $\left({ }^{\circ} \mathrm{C}\right)$, umidade relativa do ar $(\%)$, velocidade do vento $(\mathrm{m} / \mathrm{s})$, e os pesos dos machos e das fêmeas de galpão de frangos de corte com 42 dias de idade

\begin{tabular}{lrrrrr}
\hline Variáveis & Média & Mediana & \multicolumn{1}{c}{ CV } & Assimetria & Curtose \\
\hline Temperatura Ambiente $\left({ }^{\circ} \mathrm{C}\right)$ & 28,06 & 28,05 & 4,83 & 0,38 & $-0,59$ \\
Temperatura de cama $\left({ }^{\circ} \mathrm{C}\right)$ & 30,77 & 30,80 & 4,13 & 0,12 & $-0,08$ \\
Umidade Relativa do ar $(\%)$ & 78,01 & 76,90 & 4,49 & 0,94 & $-0,09$ \\
Velocidade do vento $(\mathrm{m} / \mathrm{s})$ & 1,96 & 2,00 & 31,06 & $-0,43$ & 0,53 \\
Peso do Macho $(\mathrm{kg})$ & 2,98 & 2,99 & 9,58 & $-0,08$ & 0,04 \\
Peso da Fêmea $(\mathrm{kg})$ & 2,45 & 2,44 & 7,75 & 0,32 & $-0,58$ \\
\hline
\end{tabular}

$\overline{\mathrm{CV}}=$ coeficiente de variação.

A análise dos semivariogramas para as características ambientais não indicou nenhuma direção preferencial, sendo que a variabilidade espacial dos dados ocorre da mesma maneira em todas as direções (VIEIRA et al., 2010). Os modelos estudados mostraram que as variáveis ambientais estudadas e os pesos dos animais 
nos diferentes ambientes apresentaram Grau de Dependência Espacial (GDE) forte e moderada (Tabela 2) representado pelos semivariogramas (CAMBARDELLA et al., 1994).

Os semivariogramas de temperatura de cama e temperatura do ar se ajustaram ao modelo linear, isso significa dizer que a distância entre os pontos de coleta dos dados não foram suficientes para perfeita formação dos mapas. Já os semivariogramas para umidade relativa do ar ajustaram-se ao modelo esférico, os pesos dos machos ao modelo Gaussiano e a velocidade do vento e peso das fêmeas ao modelo exponencial (Tabela 2).

Tabela 2. Modelos e parâmetros estimados dos semivariogramas experimentais para as variáveis ambientais temperatura ambiente $\left({ }^{\circ} \mathrm{C}\right)$, umidade relativa do ar $(\%)$, velocidade do vento $(\mathrm{m} / \mathrm{s})$ e os pesos dos machos e das fêmeas de galpão de frangos de corte com 42 dias de idade

\begin{tabular}{lccccccc}
\hline Variáveis & Modelo & $\begin{array}{c}\text { Efeito } \\
\text { pepita } \\
\left(\mathrm{C}_{0}\right)\end{array}$ & $\begin{array}{c}\text { Patamar } \\
\left(\mathrm{C}_{0}+\mathrm{C}_{1}\right)\end{array}$ & Alcance & $\begin{array}{c}\text { GDE } \\
(\%)^{1}\end{array}$ & Classificação & $\mathrm{R}^{2}$ \\
\hline $\begin{array}{l}\text { Temperatura } \\
\text { ambiente }\end{array}$ & Linear & 0,001 & 5,057 & 135,70 & 0,019 & Forte & 0,952 \\
$\begin{array}{l}\text { Temperatura da } \\
\text { cama }\end{array}$ & Linear & 0,707 & 4,161 & 164,10 & 16,99 & Forte & 0,989 \\
$\begin{array}{l}\text { Umidade Relativa } \\
\text { do ar }\end{array}$ & Esférico & 2,110 & 24,644 & 143,10 & 8,56 & Forte & 0,981 \\
$\begin{array}{l}\text { Velocidade do } \\
\text { vento }\end{array}$ & Exponencial & 0,270 & 0,745 & 246,10 & 36.24 & Moderado & 0,590 \\
$\begin{array}{l}\text { Peso dos Machos } \\
\text { Peso das fêmeas }\end{array}$ & Gaussiano & 0,073 & 0,333 & 312,70 & 21,92 & Forte & 0,479 \\
\hline
\end{tabular}

${ }^{1}$ Grau dependência espacial.

Segundo Miles et al. (2008) quando os semivariogramas conseguem ser ajustados a algum destes modelos, existe um ponto a partir de um determinado valor da distância entre amostras na qual não mais se observa dependência espacial, isto ocorre em função desses modelos possuírem patamares.

De acordo com o mapa de isolinhas (Figura 1) houve diferença entre pesos dos machos e fêmeas, estando esta característica em consonância com valores da linhagem Cobb para aves criadas em sistemas intensivos aos 42 dias de idade, que indicam pesos médios de $2,83 \mathrm{~kg}$ e $2,41 \mathrm{~kg}$, para machos e fêmeas, respectivamente (COOB, 2009). A distribuição dos pesos de machos e fêmeas no galpão (Figura 1) apresentou variação à medida que as mensurações se distanciavam dos exaustores, indicando variabilidade espacial e uma tendência para melhores resultados de peso dos animais que se mantiveram mais distantes do sistema de ventilação negativa.

O maior peso das aves $3,030 \mathrm{~kg}$ e $2,475 \mathrm{~kg}$ para machos e fêmeas, respectivamente, distantes dos exaustores, se deram pela existência de uma zona que mais se aproximou do conforto ótimo, condizente com as exigências das funções produtivas dos animais. Assim, as variabilidades constatadas nos mapas para as características ambientais, pode ao longo da criação, ter sido a responsável pela desuniformidade dos pesos dentro do galpão. Lu et al. (2007) relata que qualquer flutuação de calor nos valores de temperatura fora da zona de conforto, afeta 
negativamente a participação biológica da energia, promovendo menores desempenhos nos animais.

A temperatura ambiente (Figura 1) se mostrou influenciada pelas demais variáveis ambientais, ocorrendo maiores pesos dos animais onde foram observadas menores temperaturas ambientais $\left(25,5^{\circ} \mathrm{C}\right)$, e uma depreciação do peso nas áreas de temperatura mais elevadas $\left(32,2^{\circ} \mathrm{C}\right)$, respectivamente na extremidade contrária do galpão e nas proximidades do sistema de ventilação.
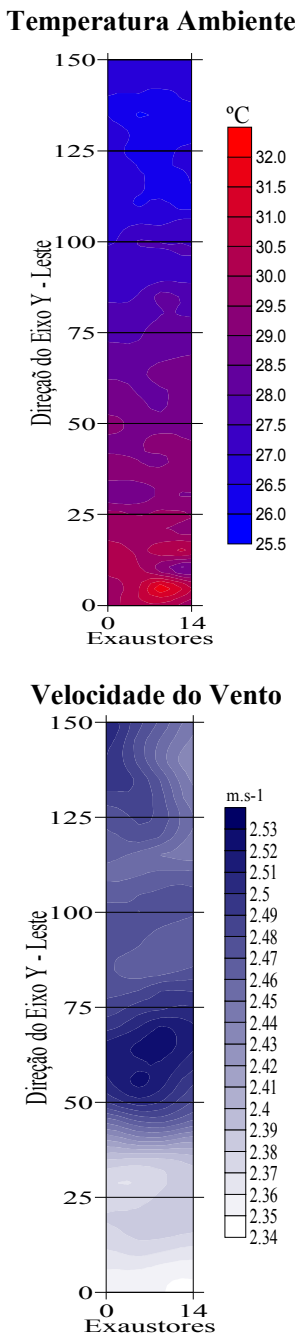
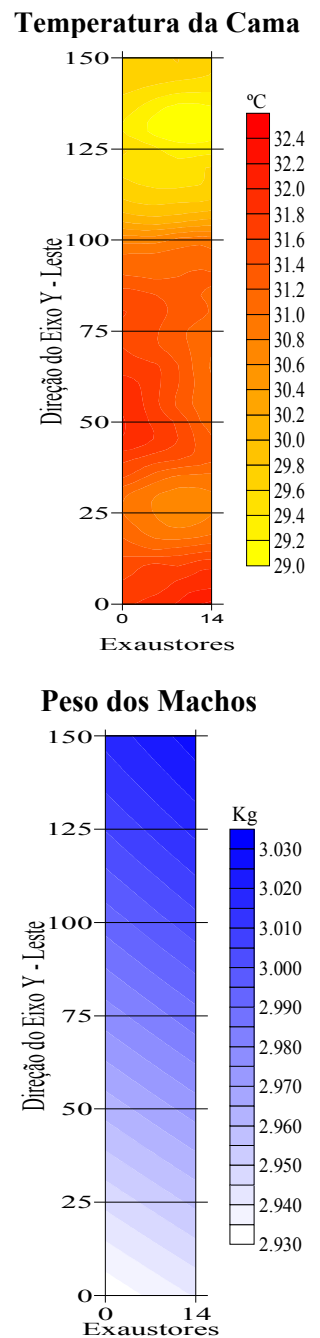

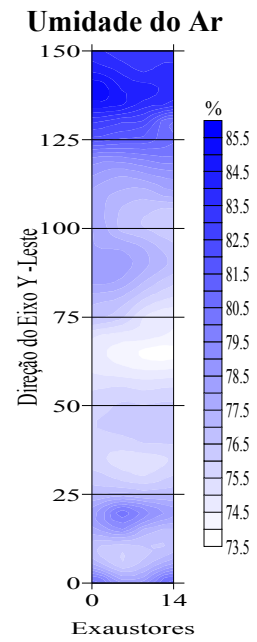

Peso das Fêmeas

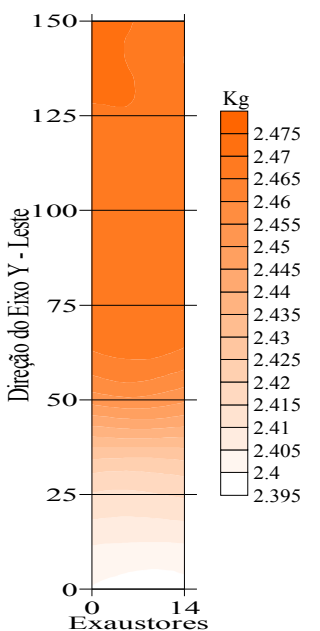

Figura 1. Distribuição espacial das variáveis ambientais temperatura ambiente $\left({ }^{\circ} \mathrm{C}\right)$, umidade relativa do ar $(\%)$, velocidade do vento (m s-1) e os pesos dos machos e das fêmeas de galpão de frangos de corte com 42 dias de idade

Segundo Medeiros et al. (2005) a máxima produtividade nas condições ambientais brasileiras é obtida sob a temperatura média de $25^{\circ} \mathrm{C}$, porém animais aclimatados podem apresentar bom desempenho em galpões com temperaturas ambiente em torno de $28^{\circ} \mathrm{C}$, valor semelhante ao da média encontrada no presente estudo que, 
no entanto, obteve resultados de peso, tanto para aves machos quanto para fêmeas, diferentes da média geral, demonstrando assim a importância do conhecimento da variabilidade espacial de variáveis ambientais.

Araujo et al. (2011) afirmaram que a temperatura que melhora as caraterísticas de desempenho como, ganho de peso e conversão alimentar, é de $20,2^{\circ} \mathrm{C}$ e $19,1^{\circ} \mathrm{C}$, respectivamente, e que o controle efetivo da temperatura ambiente pode otimizar tais variáveis refletindo assim no peso dos animais. Desta forma, pode-se, através dos resultados obtidos traçar estratégias para minimizar a variabilidade das características ambientais por toda extensão do galpão.

A cama tem por objetivo proporcionar conforto às aves, pois o frango expressa nela seu comportamento natural, manifestando a expressão de seu potencial genético e diminuindo o índice de lesões, principalmente nas criações em alta densidade (ARAÚJO et al., 2007; NAAS et al., 2007). A variável temperatura de cama (Figura 1) apresentou uma amplitude de valores que oscilaram entre $29^{\circ} \mathrm{C}$ e $32,4^{\circ} \mathrm{C}$.

Os menores valores também aferidos dentro das zonas ótimas de conforto do galpão, ou seja, locais mais distantes do sistema de ventilação, influenciaram positivamente junto com outras características nas respostas produtivas dos animais. A maior temperatura de cama pode ter ocorrido possivelmente por uma elevação da temperatura ambiente bem como da umidade da cama, o que aumenta a capacidade de fermentação, podendo atingir até $50^{\circ} \mathrm{C}$ internamente (CARVALHO et al., 2011).

Os valores referentes à umidade relativa do ar (Figura 1) variaram de $73,5 \%$ a $85,5 \%$. Os maiores valores relativos a essa variável, se mostraram distribuídos principalmente junto à entrada de ar do galpão, isto ocorreu pelo fato da nebulização neste local conseguir atingir todas as áreas, principalmente nas alturas onde as aferições foram efetuadas, ao passo que próximo do sistema de ventilação negativa, esta umidade artificial era rapidamente dispersada devido à pressão negativa exercida pelos exaustores.

A umidade relativa do ar está intrinsicamente relacionada aos processos evaporativos termorreguladores das aves. Uma maior umidade relativa associada a altas temperaturas do ar, dificulta a perda de calor animal-ambiente, incorrendo em redução do conforto e índices de produção (OLIVEIRA et al., 2006; ROCHA et al., 2010). Segundo Furtado et al. (2003) e Sarmento et al. (2005) o ambiente propício e mais confortável para o desenvolvimento das aves quanto à variável umidade relativa do ar, encontra-se na faixa de 50 a $70 \%$.

A característica velocidade do vento (Figura 1), não apresentou grande amplitude entre as velocidades mínima $(2,34 \mathrm{~m} / \mathrm{s})$ e máxima $(2,53 \mathrm{~m} / \mathrm{s})$, esses resultados se aproximam dos encontrados por Barnwell \& Rossi (2003) com velocidade do vento entre 2,29 e $2,41 \mathrm{~m} / \mathrm{s}$, porém está acima dos padrões recomendados por Medeiros et al. (2005) para a obtenção de desempenhos satisfatórios que é de $1,5 \mathrm{~m} / \mathrm{s}$. As velocidades máximas foram observadas no sentido contrário à disposição do sistema de ventilação, local da entrada de ar no galpão onde havia renovação constante do ar e encontradas as melhores zonas de conforto térmico.

Contudo, vale ressaltar a existência de uma ilha de ventilação significativa no centro do aviário, ocasionada pela presença do aquecedor utilizado na fase inicial dos animais. Esta barreira física pode ser a responsável pela elevação a partir dos $75 \mathrm{~m}$ de comprimento em direção aos exautores da temperatura ambiente e temperatura da cama.

Atribui-se, também a este fato os menores valores encontrados para umidade do ar 
Rev. Bras. Saúde Prod. Anim., Salvador, v.14, n.1, p.132-141 jan./mar., 2013 http://www.rbspa.ufba.br ISSN 15199940

entre $75 \mathrm{~m}$ e $50 \mathrm{~m}$ de comprimento, possivelmente devido a maiores valores de velocidade do vento encontrados nessa região. Segundo Calvet et al. (2010) uma adequação da taxa de ventilação permite controlar melhor a emissão de gases poluentes nos aviários, permitindo assim uma melhora do seu ambiente interno. Assim o posicionamento adequado de equipamentos utilizados em alguma das fases de criação pode influenciar a variabilidade das características ambientais e consequentemente as aves.

A desuniformidade das condições ambientais ao longo do galpão em estudo evidencia que, apesar das médias encontradas estarem próximas das preconizadas, como já discutido anteriormente, existe a necessidade de novos estudos a respeito da variabilidade das características ambientais e adoção de estratégias de manejo, bem como, de modificações estruturais na tipologia dos galpões o que vem ao encontro com sistema adotado de ventilação negativa que tem como princípio a promoção de condições ambientais semelhantes ao longo do galpão.

Todas as variáveis estudadas apresentaram de moderada a forte dependência espacial. As variáveis ambientais temperatura do ambiente, umidade relativa do ar, velocidade do vento além da temperatura de cama influenciaram diretamente o peso das aves de ambos os sexos aos 42 dias de idade.

\section{AGRADECIMENTOS}

Ao CNPq e CAPES pelo apoio com a) Bolsas no País / Mestrado, Doutorado, e Iniciação Científica - Edital MCT/CNPq n. ${ }^{\circ} 12 / 2010$ - IC, b) Edital MCT/CNPq 10/2010 - Apoio Técnico / Edital MCT/CNPq 10/2010 - AT- NS (Nivel Superior); e c) Bolsas no País / Produtividade em Pesquisa $P Q$ - 2009 - Orientador (COAGR/CGAPB/DABS). Programa de Apoio a Núcleos de Excelência PRONEX/SECT/CNPq. A Empresa Asa Norte
Alimentos que gentilmente cedeu o galpão de frango para a realização do trabalho.

\section{REFERÊNCIAS}

ARAÚJO, J.S.; OLIVEIRA, V.; BRAGA, G.C. Desempenho de frangos de corte criados em diferentes tipos de cama e taxa de lotação. Ciência Animal Brasileira, v.8, n.1, p.59-64, 2007.

ARAUJO, R.B.; FARIA, D.E.; FARIA FILHO, D.E.; LIMA, C.G.; TREVISAN, R.B.; SOUZA, K.M.R.; SAKAMOTO, M.I.; SOUZA, V.N. Modelos de superfície de resposta para predição do desempenho de frangos e elaboração de análise econômica. Revista Brasileira de Saúde e Produção Animal [online], v.12, n.3, p.770-783, 2011.

BARNWELL, R.; ROSSI, A. Maximização da performance em períodos quentes. Avicultura Industrial, v.11, p.72-80, 2003.

BORGES, S.A.; SILVA, A.V.F.; ARIKI, J.; HOOGE, D.M.; CUMMINGS, K.R. Dietary electrolyte balance for broiler chickens under moderately high ambient temperatures ande relative humidities. Poultry Science, v.82, p.301-308, 2003.

BORGES, S.A.; SILVA, A.V.F.; MAIORKA, A. Fisilogia do estresse calórico e a utilização de eletrólitos em frangos de corte. Ciência Rural, v.33, n.5, p.975-981, 2003.

CALVET, S.; CAMBRA-LÓPEZ, M.; BLANES-VIDAL, V.; ESTELLÉS, F.; TORRES, A.G. Ventilation rates in mechanically-ventilated commercial poultry buildings in Southern Europe: measurement system development and uncertainty analysis. Biosystems

Engineering, v.30, n.4, p.423-432, 2010. 
CAMBARDELLA, C.A.; MOORMAN, T.B.; PARKIN, T.B.; KARLEN. D.L.; NOVAK, J.M.; TURCO, R.F.; KONOPKA A.E. Field scale variability of soil properties in Central Iowa soils. Soil Science Society of America Journal, v.58, n.5, p.1501$1511,1994$.

CARVALHO, T.M.R.; MOURA, D.J.; SOUZA, Z.M.; SOUZA, G.S.; BUENO, L.G.F. Qualidade da cama e do ar em diferentes condições de alojamento de frangos de corte. Pesquisa Agropecuária Brasileira, v.46, n.4, p.351-361, 2011.

COBB. Suplemento de crescimento e nutrição para frangos de corte. 2009. Disponível em: $<$ http://www.cobbvantress.com/docs/default-source/cobb-700guides/cobb700-broiler-performance-andnutrition-supplement--portuguese.pdf?sfvrsn=0 $>$. Acesso em: 15 jul. 2011.

FARIA, F.F.; MOURA, D.J.; SOUZA, Z.M.; MATARAZZO, S.V. Variabilidade espacial do microclima de um galpão utilizado para confinamento de bovinos de leite. Ciência Rural, v.38, n.9, p.24982505, 2008.

FURTADO, D.A.; AZEVEDO, P.V.; TINÔCO, I.F.F. Análise do conforto térmico em galpões avícolas com diferentes sistemas de acondicionamento. Revista Brasileira de Engenharia Agrícola e Ambiental, v.7, n.3, p.559-564, 2003.

JONES, T.A.; DONNELLY, C.A.; DAWKINS, M.S. Environmental and management factors affecting the welfare of chickens on commercial farms in the United Kingdom and Denmark stocked at five densities. Poultry Science, v.84, p.11551165, 2005.

LITTLE, T.M.; HILLS, F.J. Agricultural experimentation. New York: J. Wiley \& Sons, 1978. 350p.
LU, Q.; WEN, J.; ZHANG, H. Effect of chromic heat exposure on fat deposition and meat quality in two genetic types of chicken. Poultry Science, v.86, p.10591064, 2007.

MATHERON, G. Principles of Geostatictics. Economic Geology, v.58, p.1246-1266, 1963.

MEDEIROS, C.M.; BAÊTA, F.C.; OLIVEIRA, R.F.M.; TINÔCO, I.F.F.; ALBINO, L.F.T.; CECON, P.R. Efeito da temperatura, umidade relativa $\mathrm{e}$ velocidade do ar em frangos de corte.

Engenhariana Agriccultura, v.13, n.4. p.277-286, 2005.

MILES, D.M.; ROWE, D.E.; OWENS, P.R. Winter broiler litter gases and nitrogen compounds: temporal and spatial trends. Atmospheric Environment, v.42, p.3351-3363, 2008.

NAAS, I.A.; MIRAGLIOTTA, M.Y.; BARACHO, M.S.; MOURA, D.J.; SALGADO, D.D. Qualidade da cama de frango em aviário convencional e em tipo túnel. Revista Brasileira de Engenharia de Biossistemas, v.1, p.103-116, 2007.

NAZARENO, A.C.; PANDORFI, H.; ALMEIDA, G.L.P.; GIONGO, P.R.; PEDROSA, E.M.R.; GUISELINI, C. Avaliação do conforto térmico e desempenho de frangos de corte sob regime de criação diferenciado. Revista Brasileira de Engenharia Agrícola e Ambiental, v.13, n.6, p.802-808, 2009.

OLIVEIRA, R.F.M.; DONZELE, J.L.; ABREU, M.L.T.; FERREIRA, R.A.; VIEIRA VAZ, R.G.M.; CELLA, P.S. Efeitos da temperatura e da umidade relativa sobre o desempenho e o rendimento de cortes nobres de frangos de corte de 1 a 49 dias de idade. Revista Brasileira de Zootecnia, v.35, n.3, p.797803, 2006. 
PEREIRA, D.F.; OLIVEIRA, S.C.;

PENHA, N.L.J. Logistic regression to estimate the welf are of broiler breeders in relation to environment al and be havioral variables. Engenharia Agrícola, v.31, n.1, p.33-40, 2011.

ROBERTSON, G.P. Geostatistics for the environmental sciences - GS+ User's guide. Plainwell: Gamma Design Soffware, 1998. 152p.

ROCHA, H.P.; FURTADO, D.A.; NASCIMENTO, J.W.B.; SILVA, J.H.V. Índices bioclimáticos e produtivos em diferentes galpões avícolas no semiárido paraibano. Revista Brasileira de Engenharia Agrícola e Ambiental, v.14, n.12, p.1330-1336, 2010.

SARMENTO, L.G.V.; DANTAS, R.T.; FURTADO, D.A.; NASCIMENTO, J.W.B. do; SILVA, J.H.V. Efeito da pintura externa do telhado sobre o ambiente climático e o desempenho de frangos de corte. Agropecuária Técnica, v.26, n.2, p.117-122, 2005.
SILVA, F.A.S. Software Assistat: assistência estatística. Versão 7.5 beta. Campina Grande: UAEG-CTRN-UFCG, 2008 .

SILVA, M.A.N.; BARBOSA FILHO, J.A.D.; ROSÁRIO, M.F.; SILVA, C.J.M.; SILVA, I.J.O. ; SAVINO, V.J.M.; COELHO, A.A.D. Fatores de estresse associados à criação de linhagens de avós de frangos de corte. Revista Brasileira de Zootecnia, v.36, n.3, p.652-659, 2007.

VIEIRA, S.R.; GONZALEZ GARCIA, M.A.; GONZALEZ, A.P.; SIQUEIRA, G.M. Variabilidade espacial e temporal do teor de água do solo sob duas formas de uso. Bragantia, v.69, n.1, p.181-190, 2010.

WARRICK, A.W.; NIELSEN, D.R. Spatial variability of soil physical properties in the field. In: HILLEL, D. (Ed.). Applications of soil physics. New York: Academic, 1980. p.319-344.

Data de recebimento: 30/08/2012

Data de aprovação: 04/02/2013 